\title{
Structural Inertia as a Constraint for Sustainable Development and Interregional Differences in Quality of Life Reducing
}

\author{
Elena Dotsenko ${ }^{1, *}$, Diana Galoyan ${ }^{2}$, Elena Burdenko ${ }^{1}$ and Svetlana Mudrova ${ }^{1}$ \\ ${ }^{1}$ Plekhanov Russian University of Economics, Department of Political Economy and History of \\ Economic Science, 117997, Moscow, 36 Stremyanny lane, Russia \\ ${ }^{2}$ Armenian State University of Economics, 0025128 Nalbandyan st., Yerevan, Armenia
}

\begin{abstract}
Inertia is an attribute of various systems, including sustainable development. The study of the inertia of sustainable development as a complex industrial-ecological and socio-economic supersystems is necessary to give due depth to theoretical explanations of the processes implemented in the practice of regulating industrial production, economic relations that determine the environmental load, the level of consumption of natural resources, to identify qualitative and quantitative relationships between factors of changes in structural proportions in production and consumption, their sources and relocation productive forces. The result if the study of inertia as a quality of macroeconomic structural changes, immanent to sustainable development, should be a knowledge of the forms of the transition of economic achievements of society into environmental ones. The study of sustainable development inertia is intended to improve the forecasting of various processes of interaction between man and the environment through the use of productive forces. The content of structural inertia of sustainable development can be revealed through the dynamic and actively transforming properties of structural shifts no less than through the conservatism of the structure of the economy, therefore, the creation of conditions for the regulated implementation of structural inertia, its transition into its opposite - acceleration of positive structural transformations - is associated with the regulation of economic relations in the system of environment management, production and consumption of natural resources, dynamization of changes in structural proportions between raw materials production and its processing, to overcome delaying the formation of new structural elements.
\end{abstract}

\section{Introduction}

The study of the inertia of structural changes at the categorical level, the definition of ways to accelerate them is reflected in scientific reports, sustainable development strategies of individual territories and entire states [1-4]. However, this does not diminish the debatability of the very concept of structural inertia as a quality of sustainable development. Some

\footnotetext{
*Corresponding author: ktyf110372@rambler.ru
} 
research is being made for the sources of sustainable development by fixing such fairly variable factors as investment in environmental protection, financial and social proportions of reproduction, and the ratio of intellectual and natural rent [5-8].

In the works of researchers of structural changes in the industrial economy, the lack of integrity of the theoretical apparatus for studying the inertia of sustainable development is traced. This can be explained by the distance from the philosophy of research of complex systemic economic processes and phenomena, which should include structural changes as an integral part of the transition to sustainable development. This is especially characteristic of the initial stage of research on the transformation of the reproductive system and investment relations in the starting conditions of the transition to sustainable development [9]. This stage is characterized by a significant dissociation of the analysis of investment, natural resource users' relationships, formed by newly emerging entrepreneurial firms with honest investors and the state on the one hand, and environmental impact problems on the other [10-11]. As a result, the identification of the laws of sustainable development and the dynamism of structural changes in relations in a reformed economy were ignored.

The narrowness of the methodological foundations of the study of structural inertia is observed. For the last three decades, a functional approach to the inertia of structural transformations dominated, with a dominant analysis of the problems of delayed change of public administration institutions as market-based, insignificant, by world standards, the scale of transfer and commercialization of innovations, with the oppression of the investment climate, the fiscal dominance of the commodity sector and the consolidation of the natural resource rental model economics [12-13]. As a result, the philosophy and methodology of studying structural inertia, identifying the features of cause-effect dependencies, and contradictions of sustainable development were also ignored.

\section{Materials and Methods}

In the framework of this approach, the immanence of inertia to sustainable development, the objective processes of its strengthening in the reforming Russian economy are explained by the following:

A) The Russian economy, which has undergone a transformational structural shift, is undergoing negative de-industrial transformations with a characteristic degradation of the environmental sector, with a reduction in the share of industry in GDP, and manufacturing and high-tech industries are "compressed" in its own structure [14]. On the way to neoindustrial development with deep technological modernization of basic industries and the expansion of high technologies, deep transformations of public institutions, mechanisms of interaction between business entities, psychology of entrepreneurs and officials, etc. are inevitable. In this connection, it is necessary to take into account the general property of structural transformations of socio-economic and environment management systems - the inertia, as well as expanding the time frame for change. Moreover, the essence of structural inertia can be explained from a subjective point of view - the presence of "inertia of people". Therefore, it is institutional factors - formal and informal attitudes of environmental activity - that play the role of a determining moment in the pace of structural changes in social systems.

B) The inertia of structural changes in the conditions of "long waves" in the developed countries of the world does not fully explain the problems of the evolutionary development of market reforms in the Russian economy, which arose contrary to the opinion of some economists about the positive impact of liberalization of economic relations in the transition to the environment friendly structure. On the contrary, in its structure, the Russian economy is far from technologically advanced countries, nor can it be considered market in the exact sense of this concept. At the same time, there is a rollback to the previously existing nature 
of economic relations - to building "state-and-corporate" capitalism, to replicating outdated technologies, and to strengthening anti-ecological and anti-technological decisions of the government [15].

C) Structural inertia is characteristic of any economy, and not only of the Russian one, but its strength can vary significantly. Thereafter, to overcome the inertia of structural transformations, not only the state's impact on the quantitative parameters of structural proportions (such as the industry distribution of investments, employment and output), but also the transformation of the main factors that inhibit positive structural shifts (primarily changes in the technological reproductive structure), are needed to resolve the related contradictions. Moreover, the factors determining the inertia of structural transformations of the economy themselves, in turn, are transformed in the course of reforms. This is supported, for example, by the growing mistrust of Russian economic agents in the state, the loss of the role of the environmental measures regulator by the biggest natural resources extracting companies and its transition to the state [16].

The combination of external and internal factors of the influence of timely unresolved contradictions of structural changes on the reformed economy is contradictory in itself. The inertia of such a contradictory effect of structural changes on reforms in various sectors of the economy is significantly enhanced when their state regulation does not coincide with the growth in demand for investment in innovation, with the need to intensify the introduction of innovations in mass production, with the need for new social groups of the neo-industrial type. It is in the development of regulation of the Russian innovation sphere that the state influence is more administrative, prohibitive, than in the impact on raw materials production. Selective government support for a number of major Russian companies, activation of redistribution of property in the oil and gas sector instead of stimulating investment in innovative modernization of basic industries - all this contributes to the deepening of environment protection investment contradictions and delaying their resolution [17].

Despite the specificity of the driving forces of structural changes in the reforming economy and the special nature of their inertia, it is important to remember that structural inertia is characteristic of both a developed market and a reformed Russian economy. At the same time, under the conditions of a market transformation of economic relations associated with production, with the distribution of funds, income, with state regulation of these processes, inertia is increasing in all types of structure - environmental, social, sectoral, reproductive, market-competitive, etc. However, this is exactly what the comprehensive quality of structural inertia, which takes the place of the universal property of structural changes in the economy, does not allow us to reduce it to the subjective perception of economic and ecological problems by individuals [18]. Therefore, the study of structural inertia should be based on an analysis of objective processes at the macro-, meso- and microlevels of the economy.

In this regard, it is advisable to single out the following as the main requirements for the formation of a methodology for studying structural inertia of sustainable development.

The first requirement for the formation of an approach to the study of structural inertia is the reflection of real ties in the formation of new structural proportions, which should recreate the objective logic of cognition of structural changes, their management.

The second requirement is the determination of the systemic properties of the inertia of structural changes and its analysis within the framework of the system approach, i.e. integrated, with the identification of both the inertia of the connections between intrastructural elements and the interaction of various types of the structure of the national economy with each other and with a higher-level system - the global sustainable development. Only in this way can one penetrate deep into the problems and contradictions that accompany the genesis of a structural shift in conjunction with the dynamism and cyclical nature of the economy [19-21]. With regard to structural shifts at the macro level of 
the economy, it is appropriate to assume that the inconsistency and inertia of their genesis, as their objective basis, have processes that occur both within the interconnections between structural elements and in their systemic interaction with the environment. It is in this order that global structural shifts are translated into national-economic ones, while the mismatch of the cyclic phases of global and national economic dynamics can cause significant distortions in the direction, nature and extent of the shifts. In particular, the global structural shift expected in the 2020-2030s and associated with the expansion of environment-saving technologies, with the digitalization and software of basic industries [22-24], it is building up its potential in parallel with the de-industrial structural degradation of the Russian economy [25-26].

The third requirement is the consistent solution of a number of methodological problems, which include such as highlighting the essence of structural inertia, the formation of the target apparatus for its study, determining the place of structural shifts in the analysis of cyclic dynamics, their interdependence with the transition to sustainable development.

Thus, as the goals of a systematic study of structural inertia of sustainable development in Russia, we can distinguish:

- the formation of methodological principles and theoretical foundations for analyzing the content of structural inertia, identifying its principles, contradictions, forecasting and identifying the mutual influence of structural changes and transition to sustainable development of the Russian economy as a whole;

- integration of the available theoretical foundations and methodological principles of the study of structural inertia of sustainable development and its regulation;

- assistance in creating the conceptual framework for structural inertia regulation, with the aim of accelerating positive structural changes through the timely resolution of their contradictions;

- theoretical and practical support for the regulation of structural changes in order to overcome their inertia.

\section{Results and Discussion}

The forgoing gives reason to believe that the appearance and strengthening of structural inertia of sustainable development is caused by progress in the expansion of some elements of the structure of the economy to the detriment of others. For example, the increase in output, export and investment in the raw materials sector of the Russian economy, the dominance of mining, oil extracting, metallurgical companies in listings of stock exchanges, including world ones, largely contributed to the stagnation of the manufacturing, high-tech and social sectors. Also, administration, voluntarism of the state in the system of commercialization of innovations, their inter-sectoral transfer and global diffusion, the growth of the shadow sector are detrimental to other processes in the structure of the Russian economy - the development of market competition, the formation of a small innovative business, accelerated replacement of capital goods. That is, structural regression can be caused by the preservation of obsolete forms or subjects of economic relations in the economic system.

An analysis of structural inertia will be difficult without taking into account the limited influence of structural changes on the dynamics and cyclicality of reproduction processes, in which the formation and development of new inter-subject relationships of environmental measures in the economy are manifested. This is due primarily to the fact that structural inertia is associated not only with the state of development of an individual object, but with a whole set of connections, therefore, when studying inertia in the nucleation and realization of a structural shift, it should be separated from stagnation.

Stagnation, including the environmental one, can be represented as a certain process, due to the modification of the manifestation of the inherent property of natural and social systems 
to conservation and reproduction, to the continuous extension of functioning in conditions of increasing fluctuations. In general, inertia and stagnation can be divided as follows. Stagnation is mainly associated with the destructive nature of the change in intra-system connections and the loss of some important functions of the system, despite the fact that the system itself continues to function. Inertia, in turn, reflects another immanent property of the system - to maintain its integrity. Therefore, in order for the structure of the economy to be able to reproduce its functions, their constant change is required with the preservation of important relations between its elements. From this point of view, inertia can be defined not as a continuation of unnecessary functioning or preservation of an obsolete structure, but as an indicator of the stability of the socio-economic and environment systems, as the ability to continue sustainable development.

This is the different meaning that structural inertia and stagnation have in relation to the driving forces of structural shifts. We can assume that inertia carries a certain development potential, since it assumes the stability of the structure of the economic system, its reproduction. As applied to the theory of structural shifts as processes modernizing the economy, this means that a positive structural shift, in order to spread throughout the entire economic mechanism, must have an initial basis in the form of developed economic relations in the reproductive, social, environmental and technological spheres. In practice, the new should be more effective, attractive to economic agents, than the old. Therefore, despite the fact that the generally accepted characteristic of inertia itself is the reproduction of the traditional and the ability of the system to withstand the innovative, structural inertia is inseparable from the acceleration of the national economy, from the development of the innovation process in it.

The existence of structural inertia means the gradual change in the qualities of certain relationships in the economy and the different rates of development of their subjects, the proportions of their use of production factors. Consequently, individual firms, business communities, subsystems of the economy, industries, sectors and segments of the economy have different inertia. This means that they have different effects on structural transformations, on the change in interactions with natural environment. From this it also follows that the structural proportions of the economy change more slowly, the greater the strength of their inertia; the same can be said about the relationships between them. All this gives reason to present structural inertia as a mechanism for the interaction of subjects of sustainable development with their external environment in a particular system, as well as a mechanism for maintaining the integrity of these relationships, ensuring the reproduction of structural proportions, inter-element relationships and the economy as a whole.

Due to the fact that, as a rule, unbalanced forces act on any system, the study of the conditions for the realization of structural inertia in conjunction with the acceleration of transition to sustainable development, and the formation of progressive forms of various relationships in the economy, while preserving the old, conservative ones, is of particular importance. Along with the indisputably objective form of expression, structural inertia has a subjective side. It manifests itself in the fact that inertia is not a problem until it is defined as a problem for those economic entities in the movement of which it manifests itself. The problem of realizing structural inertia to transform certain types of economic structure arises when the balance of inertial and accelerated, traditional and innovative is violated under the influence of both objective and subjective factors of sustainable development.

The subjective side of structural inertia of sustainable development is due to the inertia of human thinking, manifested in the actions of government representatives of their large corporations - natural resource producers, major national exporters and importers, employers. In addition, the inertia of economic thinking can manifest itself not only in economic practice (in relation to investing in innovations, the formation of a regulatory framework for this process), but also at the level of scientific abstraction. The poverty of the 
methodology for studying structural convergence, the relationship of cyclic dynamics and structural changes, the weakness of the theoretical basis for the analysis of their relationships with the deep layers of the transformation mechanism causes inattention to the most important aspects of the genesis of a positive structural shift. These aspects include, first of all, reproduction processes, such as an increase in the rate of accumulation, accelerated renewal of fixed capital, redistribution of investment resources between sectors of the economy, and bringing government influence on the investment system in line with the requirements of accelerated sustainable development.

Structural inertia as an economic category should be used to study the dynamics of economic development, the stability of individual structural proportions in the economy, when determining the ways of interaction between economic entities and the external environment and the structural changes that arise in this process (such as the growth of the raw material specialization of the country's economy, the slowdown in foreign investment and other). Thus, the content of structural inertia can be generalized through the objective existence in the economy of a number of processes caused by it.

Firstly, through a change in the mass of certain indicators that determine the basic structural proportions - the sectoral distribution of GDP, employment and investment, the technological identity of the economy to specific technological structures, the structure of sustainable social groups and the place of ecological entrepreneurship in them.

Secondly, through the duration of existence and the ratio of opposing factors of structural changes - advanced and conservative, new and old, developing and stagnating.

Third, through the timeliness or delay in resolving the contradictions of structural changes.

Fourth, through the ratio of quantitative and qualitative changes in structural proportions, as well as through the interaction of the objective and subjective in the process of structural transformations. Consequently, the general theoretical meaning of structural inertia in economics can be explained as follows: inertia is a qualitative property of sustainable developing, that is, in motion, phenomenon, therefore, inertia as a property of a structural shift cannot be completely separated from the acceleration of its course, both as a whole and regarding its individual sides (reproduction, industry, innovation and technology, etc.). From a methodological point of view, this is due to the fact that the various relationships in the economy that form its structural proportions are inherently controversial.

\section{Acknowledgement}

The reported study was funded by the grant "The mechanism of consolidation of the principles of knowledge and digital economy to ensure an increase in entrepreneurial culture and reduce interregional differences in the level and quality of life of the population in accordance with the main directions of the spatial development strategy of the Russian Federation until 2025".

\section{Conclusion}

The nature of structural inertia lies in the essence of the development of a structural shift an important form of economic movement towards sustainable development. The main content of the inconsistency of the development of structural changes lies in the unity of stability and variability of this process. Structural deformations of the Russian economy suggest an impact on the inter-element relations in it and on the relations formed during their interaction, from the outside in one form or another. Accordingly, a decrease in the impact 
of positive (that is, desirable for sustainable development) forces leads to a slowdown in structural transformations due to an increase in structural inertia.

The system of structural transformations of the economy has dynamic stability, which allows it to maintain the basis of its design - a significant number of entities that are in constant interaction with each other. Accordingly, such dynamic stability of the structural transformation is determined by the objective properties of the structure, therefore, maintaining the trajectory of sustainable development can also be attributed to the property of structural inertia. This creates instability of positive structural changes in the country's economy and, at the same time, their inertia.

\section{References}

1. Yu. A. Zhuravsky, Economics and Innovation Management, 4, 20-34 (2019) DOI: 10.26730/2587-5574-2019-4-20-34

2. M. Hannan, J. Freeman, American Journal of Sociology, 82:5, 929-964 (1977)

3. W. B. Arthur, Econ. J., 99:394, 116-131 (1989)

4. D. Puffert, Encyclopedia, 12, 1020 (2003)

5. E. V. Slesarenko, Economics and Innovation Management, 4, 4-15 (2018) DOI: 10.26730/2587-5574-2018-4-4-15

6. Klimovich, M.A. Gasanov, Economics and Innovation Management, 2, 8-17 (2019) DOI: 10.26730/2587-5574-2019-2-8-17

7. S. Zhironkin, O. Aleshina, V. Gorev, Y. Gunyakov, O. Zhironkina, E3S Web Conf., 105, 04001 (2019)

8. S. Zhironkin, M. Cehlar, V.Zhironkin, E3S Web Conf., 134, 03013 (2019)

9. S. Zhironkin, S. Demchenko, G. Kayachev, E. Taran, O. Zhironkina, E3S Web Conf., 105, 03008 (2019)

10. V. Zhironkin, J. Janocko, E3S Web Conf., 134, 02002 (2019)

11. V. Frolova, O. Dolina, T. Shpilkina, E3S Web of Conf., 105. 01054. (2019)

12. M. Anastasov, N. Kazitskaya, I. Politkovskaya, E3S Web of Conf., 105. 04043. (2019)

13. O. Borisova, V. Frolova, L. Artamonova, E3S Web of Conf., 105. 04047. (2019)

14. O. Miliushenko, A. Kovalev, M. Zhidkova, E3S Web of Conf., 105. 04046. (2019)

15. O. Ivanenko, E3S Web of Conf., 105. 04025. (2019)

16. Shavina E., Fisunov S., E3S Web of Conferences 105, 04018 (2019)

17. O. Kalenov, S. Kukushkin, R. Kamanina, E3S Web Conf., 105, 04028 (2019)

18. S. Kukushkin, O.Kalenov, E3S Web Conf., 105, 04022 (2019)

19. Kalenov, O., Shavina, E., E3S Web of Conferences 41, 04054 (2018)

20. T. Gvozdkova, M. Tyulenev, S. Zhironkin, V. A. Trifonov, Yu. M. Osipov, IOP Conf. Ser.: Earth Environ. Sci., 50:1, 012010 (2017)

21. M. Cehlar, Economics and Innovation Management, 3, 24-31 (2019) DOI: 10.26730/2587-5574-2019-3-24-31

22. A. L. Volkova, O. U. Korneva, Economics and Innovation Management, 2, 32-38 (2019) DOI: $10.26730 / 2587-5574-2019-2-32-38$

23. T. V. Kiseleva, V. G. Mikhailov, Ya. S. Mikhailova, Economics and Innovation Management, 3, 62-68 (2019) DOI: 10.26730/2587-5574-2019-3-62-68 
24. S. K. Demchenko, M. S. Zlotnikov, T. A. Melnikova, O.S. Demchenko, International Journal of Civil Engineering and Technology, 10:2, 1877-1884 (2019)

25. M. S. Zlotnikov, V. V. Telnykh, S. I. Mutovin, S. K. Demchenko, J.J. Suslova, Journal of Environmental Management and Tourism, 8:2, 366-372 (2017)

26. S. K. Demchenko, J. J. Suslova, A. S. Yamschikov, I. R. Ruyga, T. A. Melnikova, Journal of Applied Economic Sciences, 12:1, 194-205 (2017) 